\title{
ATIVISMO JUDICIAL, DISCRICIONARIEDADE E CONTROLE: UMA QUESTÃO HERMENÊUTICA?
}

\section{Nagibe de Melo Jorge ${ }^{1}$}

\section{Resumo:}

O artigo analisa o problema da justificação, legitimação e controle do ativismo judicial a partir da visão hermenêutica tradicional e propõe a fundamentação da decisão judicial com base em critérios lógicos e nas regras da argumentação como uma solução possível para o problema.

Palavras-Chave: Ativismo Judicial. Legitimação. Decisão Judicial. Fundamentação. Argumentação.

\section{INTRODUÇÃO}

O pós-positivismo, sem nenhuma dúvida, ampliou o espaço criativo da atividade jurisdicional, a discricionariedade dos juízes. Esse fenômeno tem sido objeto de uma especial atenção, ora apreensiva, ora esperançosa, da comunidade acadêmica nacional e internacional, produzindo muitos estudos e acalorados debates, que se desenvolvem sobretudo ao redor de duas vertentes: a) quais os limites da atividade criativa dos juízes?; b) quais os métodos hermenêuticos adequados para a interpretação das normas constitucionais de textura aberta?

O progressivo empoderamento do Poder Judiciário ao redor do mundo ${ }^{2}$, no entanto, é um fato incontornável. Não se trata mais de perguntar sobre sua possibilidade ou sobre os seus limites, na medida em que a existência de cortes constitucionais com poderes suficientes para pelo menos invalidar normas produzidas pelo Poder Legislativo à luz da interpretação mais ou menos abrangente que dão às normas constitucionais é uma realidade na maioria dos países do mundo ocidental ${ }^{3}$. A pergunta acerca dos métodos

\footnotetext{
${ }^{1}$ Juiz Federal. Mestrado em Direito (Direito e Desenvolvimento) pela Faculdade de Direito da Universidade Federal do Ceará. Professor da Faculdade Christus. Professor convidado da Escola Superior de Administração Fazendária - ESAF, da Escola da Magistratura do Estado do Ceará - ESMECE e da Escola da Magistratura do Estado de Sergipe - ESMESE. E-mail: nagibemj@uol.com.br

2 Sobre o tema cf. TATE, C. Nela; VALLINDER, Torbjrn. The global expansion of judicial power. NewYork: NYU Press, 1997.

${ }^{3}$ Até mesmo o Reino Unido, onde vigia o princípio da Supremacia do Parlamento, e a França, que até recentemente adotava o controle prévio de constitucionalidade por um órgão interno ao próprio Parlamento, passaram por importantes reformas na última década. Em 2005 foi aprovado o Constitutional Reform Act que criou, a partir de outubro de 2009, a Suprema Corte do Reino Unido com estrutura desvinculada do Parlamento e bem mais parecida com o modelo norte-americano. Sobre a influência da Convenção Europeia dos Direitos Humanos de 1953 e da comunidade internacional na aprovação do Human vol.07, no. 02, Rio de Janeiro, 2014.p. 509-532 509
} 
hermenêuticos mais adequados para a interpretação das normas constitucionais tem contribuído para a produção de um vasto e importante instrumental técnico para a interpretação das normas constitucionais pelas cortes constitucionais e pelos juízes. É inegável sua importância.

Entretanto, nenhum desses métodos tem o poder de vincular os juízes a um procedimento interpretativo específico. A escolha por um dos métodos hermenêuticos raramente é feita de modo claro pelas cortes e, na prática, resolve-se em uma questão argumentativa e não propriamente hermenêutica. Não queremos com isso sugerir a menor importância do estudo da hermenêutica do ponto de vista filosófico nem de seus métodos aplicados especificamente à ciência jurídica. Mas, se queremos falar de controle e legitimação da atividade jurisdicional é preciso ir além. Uma questão jurídica posta à decisão dos juízes sempre se resolve por meio de uma atividade argumentativa. É essa atividade que merece ser observada e cuidadosamente estudada se quisermos perquirir acerca do controle da atividade jurisdicional, sobretudo no que diz especificamente com a atividade criativa dos juízes.

Não é objetivo deste breve ensaio a investigação da atividade argumentativa quando da decisão judicial (aplicação ou criação do Direito). Queremos, antes e apenas, chamar a atenção para a importância da seguinte questão: como legitimar e controlar a atividade criativa dos juízes? A resposta para essa pergunta parece estar nos postulados da argumentação investigados pela filosófica da linguagem e pela lógica informal. Uma vez mais, não pretendemos (nem poderíamos no espaço deste artigo) apresentar ou analisar esses postulados.

Se conseguirmos abrir uma pequena trilha de possibilidades para resposta daquele questionamento à luz da teoria da argumentação e da lógica informal, reposicionando o papel da hermenêutica constitucional em dar resposta a esse problema, teremos razoavelmente alcançado o intento. Para isso, investigaremos brevemente a atividade criativa dos juízes, o chamado ativismo judicial e a discricionariedade dos julgadores e, em seguida, apresentaremos alguns critérios que têm sido usados ou sugeridos como capazes de justificar a atividade criativa dos juízes, tentando evidenciar algumas de suas limitações.

Rights Act, de 1998 e, posterior, ainda que não trate diretamente desse assunto, do Constitucional Reform Act cf. BARBÉ, Vanessa. Le Human Rights Act 1998 et la souveranité parlamentaire. In: Revue Française de Droit Constitutionnel. Anne 2005. Vol. 61. Paris: Presses Universitaires de France, 2005. p. 117-145. A França, a seu turno, aprovou uma Reforma Constitucional em 23 de julho de 2008, que veio possibilitar o controle repressivo de constitucionalidade pelo Conselho Constitucional francês. Sobre a reforma francesa cf. CUNHA JÚNIOR, Dirley da. O controle de constitucionalidade na França e suas alteraçóes advindas da reforma constitucional de 23 de julho de 2008. Disponível em < http://portalciclo.com.br/downloads/artigos/direito/O_Controle_de_Constitucionalidade_na_Franca_e_as_Alteracoes _advindas_da_Reforma_Constitucional_de_23_de_julho_de_2008.pdf $>$. Acessado em 19/11/ 2013 . 


\section{O ATIVISMO JUDICIAL}

A doutrina sofre em definir e caracterizar o ativismo judicial. Mais difícil ainda é estabelecer se o ativismo judicial é algo positivo para a democracia e para a implementação dos direitos fundamentais. $\mathrm{O}$ fenômeno ora é visto como algo positivo, ora como algo negativo. Mais recentemente tem sido relacionado com uma censurável exacerbação dos poderes dos juízes, que invadiriam indevidamente a esfera dos Poderes Executivo e Legislativo, a fim de firmar, sem a necessária legitimação democrática, o seu próprio poder: a ditadura dos juízes; nesse sentido é visto como um comportamento deletério para a democracia e para a separação de poderes ${ }^{4}$.

O ativismo judicial está relacionado à interpretação e à criação do Direito, em uma perspectiva de graus. Poderíamos estabelecer, em um primeiro momento, que quanto mais os juízes se atenham ao significado literal do texto normativo, menos ativistas serão; ao contrário, quanto mais livres considerem-se para interpretar o texto normativo, trazendo-lhe significados novos e até argumentos extrajurídicos e desvinculá-lo da letra da lei, mais ativistas serão.

O ativismo judicial tem a ver com a transformação do papel do Poder Judiciário ocorrida nos últimos duzentos anos. Paulatinamente, os juízes deixam de ser meros aplicadores da lei, "la bouche de la lop", na expressão de Montesquieu e tornaram-se coautores do significado da norma. Esse movimento se deve a muitos fatores, mas, sobretudo, ao desencanto com as possibilidades de certeza trazidas pela filosofia positivista, de um mundo inteiramente mecanizado e dominado de maneira previsível pela razão humana, bem como ao desenvolvimento da ideia de normas superiores que se sobreporiam às normas ordinariamente

\footnotetext{
${ }^{4}$ Segundo Elival da Silva Ramos, "[a]o se fazer menção ao ativismo judicial, o que se está a referir é à ultrapassagem das linhas demarcatórias da função jurisdicional, em detrimento principalmente da função legislativa, mas, também, na função administrativa e, até mesmo, da função de governo. Não se trata do exercício desabrido da legiferação (ou de outra função não jurisdictional), que, aliás, em circunstâncias bem delimitadas, pode vir a ser deferido pela própria Constituição aos órgãos superiores do aparelho judiciário, e sim da descaracterização da função típica do Poder Judiciário, com incursão insidiosa sobre o núcleo essencial de funções constitucionalmente atribuídas a outros Poderes". (Ativismo judicial: parâmetros dogmáticos. São Paulo: Saraiva, 2010.p. 116-117)

${ }^{5} \mathrm{Na}$ doutrina americana, o ativismo judicial (judicial ativism) contrapõe-se à autocontenção judicial (judicial restraint ou judicial self-restraint). Segundo Posner, o termo judicial self-restraint é um camaleão; dos muitos significados que os autores atribuem a ele, três mais importantes devem ser destacados: (a) os juízes aplicam a lei, eles não a criam; (b) os juízes devem ser deferentes em grande extensão às decisões de outras autoridades: os juízes de apelação devem ser deferentes aos juízes de primeiro grau e todos os juízes às decisões dos Poderes Legislativo e Executivo; (c) os juízes são altamente relutantes em declarar inconstitucional os atos dos Poderes Legislativo e Executivo (POSNER, Richard A. The rise and fall of judicial selfrestraint. In: California Law Review. Vol. 100. No. 3. June 2012. p. 519-556. p. 520-521.). Posner relaciona o fim da tradição de self-restraint inaugurada por um artigo de 1893 do professor de Harvard James Bradley Thayer com o surgimento da Teoria constitucional ou de diversas teorias constitucionais que acabaram por confundir e afastar os termos de seu sentido original; para ele, '[t]he terms 'judicial restraint' and judicial self-restraint' survive, but as vague, all-purpose complimentes; 'judicial activism' survives as a vague, all purpose pejorative. Their original meanings have largely benn lost." (Ibid., p. 533). No presente estudo utilizaremos o termo ativismo judicial para referir à atividade criativa dos juízes além do que seria esperado em uma interpretação literal do texto da lei e em uma leitura tradicional do princípio da separação dos poderes.
} 
criadas pelos parlamentos. André Ramos Tavares enfatiza dentre esses fatores a proteção dos direitos humanos por meio dos princípios, pela supremacia da Constituição, pela vinculação do legislador aos direitos fundamentais e, sobretudo, pela necessidade de retirar do espaço político certas opções:

Em síntese, percebe-se que a ampliação do espaço "tradicional" do juiz constitucional (entre Judiciário e Tribunal Constitucional), na tutela da Constituição e sua supremacia (quer dizer, para além de um mero legislador negativo, na expressão cunhada por Kelsen) foi viabilizada, dentre outras ocorrências, pela abertura semântica das constituições, em sua contemplação principiológica do discurso dos direitos humanos, pela supremacia da Constituição, pela vinculação dos legislativos aos direitos fundamentais consagrados e, sobretudo, pela necessidade de retirar do espaço político certas opções. ${ }^{6}$

Declarar, como fez James Marshall, que a Constituição é superior às demais leis e, além disso, que dá aos juízes o poder de invalidar as leis produzidas pelos legisladores quando estas não estiverem de acordo com a norma constitucional foi um passo decisivo rumo ao ativismo judicial. Parece certo que o ativismo judicial apoia-se, em larga medida, na possibilidade de controle de constitucionalidade das normas elaboradas pelos legisladores e na possibilidade de preenchimento do conteúdo de certas normas jurídicas, seja por seu conteúdo semântico intencionalmente $a^{b e r t o}{ }^{7}$, como no caso dos princípios constitucionais, seja para a correção de ambiguidades decorrentes de conflitos próprios da atividade legislativa ou, ainda, em virtude da modificação do sentido da norma ao longo do tempo.

Sobre a atividade legislativa três fatores merecem ser destacados: (a) de um lado, não é a melhor representação da verdade a afirmação de que os representantes do povo representem, de fato, os interesses do povo. O que se vê é que deputados e senadores acabam representando interesses de alguns grupos "que têm superior capacidade de organização, normalmente grupos que possuem invejável força econômica, deixando em segundo plano, até mesmo, os programas dos partidos políticos a que são filiados”; (b) de outro lado, em uma sociedade complexa como a que vivemos, é impossível que o Poder Legislativo produza normas de sobre todos os aspectos da vida social (esse é um problema de quantidade); (c) além disso, as normas produzidas frequentemente refletem as correntes em conflito no parlamento e, por isso, deixam muitos pontos obscuros e ambíguos, do contrário o consenso mínimo não seria alcançado para a própria edição da norma (esse é um problema de qualidade ou grau). Sendo assim, as leis não formam, pelo menos não em um primeiro momento, um sistema coerente e completo. A coerência e completude do ordenamento são produzidas pela

\footnotetext{
${ }^{6}$ TAVARES, André Ramos. Paradigmas do judicialismo constitucional. São Paulo: Saraiva, 2012. p. 66.

${ }^{7}$ H. L. A. Hart adverte que "[a] textura aberta da lei significa que há, de fato, áreas de conduta em que muito deve ficar para ser desenvolvido pelos tribunais e autoridades públicas, balanceando, à luz das circunstâncias, os interesses conflitantes, os quais variam de peso caso a caso". (Apud. RAMOS, Elival da Silva. Ibid., p. 121)

${ }^{8}$ JORNE NETO, Nagibe de Melo. O Controle jurisdicional das políticas públicas: concretizando a democracia e os direitos sociais fundamentais. Salvador: Edições JusPODIVM, 2008. p.87.
} 
interpretação e criação normativa feitas pelos juízes. Sendo assim, a criação do Direito pelos juízes é uma necessidade insuperável, como adverte John Ely:

Of course courts make law all the time, and in doing so they may purport to be drawing on the standard sources of the non interpretativist - society's "fundamental principles" or whatever - but outside the area of constitutional adjudication, they are either filling in gaps the legislature has left in the laws it has passed or, perhaps, taking charge of an entire area the legislature has left to judicial development.9

O ativismo judicial no sentido de maior ou mais ousada criação do direito por parte dos juízes é, portanto, uma decorrência lógica do pós-positivismo, que se caracteriza pela normatização de conteúdos axiológicos por meio dos princípios, normas de textura aberta, isto é, de conteúdos não imediatamente definíveis. A concretização dos princípios, no momento da aplicação do Direito, passa necessariamente pelo preenchimento da norma por meio da criação de significantes, não mais pela mera descoberta significados ${ }^{10}$. Os juízes deixam de ser meros intérpretes de um texto normativo com conteúdo mais ou menos evidente e passam a ser criadores do conteúdo significante dos princípios.

Na doutrina constitucional norte-americana, o ativismo judicial muitas vezes é entendido como uma disputa entre interpretativistas e não interpretativistas, sendo aqueles os que defendem que os juízes devem se limitar, na resolução das questões constitucionais, às normas que estão expressas ou claramente implícitas no texto da Constituição; e estes os que defendem que os juízes poderiam ir além dessas referências normativas e considerar normas que não estão claramente estabelecidas nos limites do texto constitucional. ${ }^{11}$ Para John Hart Ely, o interpretativismo está relacionado com o positivismo, assim como o não interpretativismo está relacionado com o direito natural ${ }^{12}$.

Aqui, o positivismo aparece como um ideal de cientificidade, entendido como a possibilidade de racionalidade, mecanicidade, repetibilidade e segurança das decisões. Já o direito natural está relacionado com a racionalidade, mas de um modo diferente, na medida em que as soluções, ditadas em primeiro lugar pela razão, podem ter fundamento em normas morais supra legais. Os direitos fundamentais e os princípios jurídicos assegurados pela Constituição têm feito as vezes dessas normas morais supralegais.

${ }^{9}$ ELY, John Hart. Democracy and distrust: a theory of judicial review. Cambridge and London: Harvard University Press, 2002. p. 4.

${ }^{10}$ A teoria do signo, tal qual apresentada por Saussure, vê o signo como uma entidade bifásica formada pelo significante e pelo significado. "Com efeito, distingue-se, analiticamente, no interior do signo, dois elementos ou planos conceituais: o indício material ou significante (som, sinal, grafia, gesto, comportamento, objeto, imagem), situado no plano da expressão; e o conteúdo significado, situado no plano da interação (fenômeno, fato)" WARAT, Luis Alberto. O Direito e sua linguagem. 2 ed. Porto Alegre: Sergio Antonio Fabris Editor, 1995. p. 25. Nesse sentido, o ativismo judicial alargaria ou modificaria os significantes dispostos na letra da lei para abranger novos significados.

${ }^{11}$ ELY, John Hart. Democracy and distrust: a theory of judicial review. Cambridge and London: Harvard University Press, 2002.p. 1.

${ }^{12}$ Ibid. p. 1 (nota de rodapé). 


\section{A BUSCA PELA LEGITIMAÇÃO DA ATIVIDADE CRIATIVA DOS JUÍZES}

No estágio atual da cultura jurídica ocidental, parece inafastável e irrevogável o novo papel assumido pelo Poder Judiciário como co-criador de significantes normativos. Cappelletti apresenta muito bem essa ideia, dizendo ser impossível qualificar a criatividade dos juízes como maléfica ou beneficia sem que se analise um conjunto de outras circunstâncias:

Trata-se, em minha opinião, de problema que não se pode resolver com um claro sim ou não à criatividade dos juízes. Tal criatividade, - ou para ser mais preciso, alto grau de criatividade, pois bem vimos como se trata essencialmente de um problema apenas de natureza quantitativa -, pode ser benéfica ou maléfica, segundo as muitas circunstâncias contingentes, de tempo e lugar, de cultura, de necessidades reais de determinada sociedade, circunstâncias, de mais a mais, de organização e estrutura das instituições e, não por último, dos tipos de magistratura que exercem tal criatividade. ${ }^{13}$

A questão que propomos neste ensaio é a seguinte: podemos estabelecer limites ao ativismo judicial e, portanto, à atividade criativa e à interpretação judicial, de forma a assegurar a legitimidade das decisões, a preservação da separação de poderes e a maior promoção dos direitos e garantias fundamentais, inclusive, dos direitos fundamentais sociais? Que limites seriam esses?

Elival Ramos adverte com precisão que, desde que Kelsen ${ }^{14}$ revisou a teorização clássica do binômio interpretação-aplicação da lei e evidenciou o tema da discricionariedade judicial, entendida esta como espaço de liberdade do julgador e banindo-a das preocupações da Dogmática Jurídica, para relegá-la ao território da Política do Direito, pouca atenção tem sido dada aos limites ou critérios que poderiam controlar ou legitimar essa discricionariedade.

Uma vez formado um relativo consenso sobre a ideia de que as decisões judiciais constituem manifestação do poder discricionário inerente à atividade interpretativa, ao contrário do que se poderia imaginar, a temática continuou a provocar interesse relativamente reduzido nos cultores do Direito Processual ou do Direito Constitucional. A razão para isso reside na utilização pragmática do conceito de discricionariedade, que, em última análise, serve para tornar menos intenso o controle jurídico sobre determinados atos do Poder Público, exatamente em virtude da liberdade de escolha no tocante a alguns aspectos de sua prática. ${ }^{15}$

Mauro Cappelletti, ao analisar a questão da legitimidade da atividade criativa dos juízes, retoma a questão da legitimidade da atividade interpretativa dos juízes, pretendendo justificá-la por meio do procedimento adotado. Segundo Cappelletti, a atividade jurisdicional diferencia-se da atividade legislativa pelo

\footnotetext{
${ }^{13}$ CAPPELLETI, Mauro. Juízes legisladores? [Tradução: Carlos Alberto Alvaro de Oliveira]. Porto Alegre: Sérgio Antonio Fabris Editor, 1993.p. 92.

${ }^{14}$ Segundo Kelsen, "[é] desacertado distinguir entre atos de criação e atos de aplicação do Direito. Com efeito, se deixarmos de lado os casos-limite - a pressuposição da norma fundamental e a execução do ato coercitivo - entre os quais se desenvolve o processo jurídico, todo ato jurídico é simultaneamente aplicação de uma norma superior e produção, regulada por esta norma, de uma norma inferior". (KELSEN, Hans. Teoria pura do direito [Tradução: João Batista Machado]. São Paulo: Martins Fontes, 2003.)

${ }^{15}$ RAMOS, Elival da Silva. Ativismo judicial: parâmetros dogmáticos. São Paulo: Saraiva, 2010.p. 122. 
procedimento. Segundo ele, o procedimento jurisdicional é fundado em três regras básicas: (a) Nemo judex in causa própria - o juiz não pode julgar a própria causa nem nenhuma causa que possa ter interesse próprio; (b) audiatur et altera pars - o juiz deve estar posicionado supra partes, em uma posição imparcial e equidistante, independente, livre de pressões das partes; (c) ibi non estactio, ibi non est jurisdiction - o juiz deve atuar somente quando provocado pelas partes, justamente para garantir a regra anterior.

Milênios de sapiência humana encontram-se concentrados, na verdade, para além da rotina, nas chamadas regras fundamentais da "justiça natural" ou "natural justice", que antecedem ao próprio nascimento dos sistemas de "Common Law", e que encontraram a sua mais incisiva expressão em dois aforismos do antigo saber latino, "nemo judex in causa própria" e "audiatur et altera par"16.

Essas regras, na medida em que limitam a atividade dos juízes, vez que só poderiam exercer o poder sob estas condições, legitimariam o ativismo judicial. Nada obstante, não são capazes de oferecer, por si sós, a garantia de que o ativismo judicial será exercido do modo mais benéfico e desejável. É claro que fixar o que seria benéfico e desejável para fins de exercício do ativismo judicial já é, por si só, um problema que chega a ser insuperável se não aceitarmos algumas premissas.

De fato, alguns defendem que o pós-positivismo e a possibilidade de preenchimento de conteúdo normativo pelos julgadores é, em si mesmo, um mal que deve ser a todo custo evitado a fim de garantir a separação de poderes e assegurar que as decisões políticas sejam discutidas e adotadas por quem tem legitimidade democrática e competência para tanto: a esfera política. Os juízes, além de não terem legitimidade, não teriam capacidade para resolver algumas questões, sobretudo quando tivessem que se embasar em argumentos extrajurídicos e procurar respostas diretamente na realidade social. Assumimos aqui, entretanto, que o pós-positivismo e a normatização de valores nos textos constitucionais, na quadra atual, caracterizada por uma sociedade complexa onde as possibilidades fáticas superam infinitamente as possibilidades de normatização pelo corpo legislativo, são realidades inafastáveis.

Cappelletti admite que a atividade jurisdicional padece de algumas debilidades, sendo as principais: (a) informação inadequada; nesse ponto podemos também acrescentar casuísmo e incoerência nas decisões, o que ofenderia o princípio da isonomia. (b) eficácia retroativa das decisões judiciais, o que leva ao casuísmo; (c) incompetência institucional por falta de elementos para a tomada de decisão; e, sobretudo, (d) caráter não majoritário das decisões.

O direito judiciário é casuístico, de modo frequente bastante "causal", descontínuo e, em grande medida, dependente da sorte de determinados casos concretos. Mesmo quando integrado pelo direito legislativo, e assim tornado menos "esporádico", o resultado constitui, amiúde, confusa mistura de fontes jurídicas diversas, muitas vezes conflitantes

${ }^{16}$ CAPPELLETI, Mauro. Op. cit., p. 75. 
entre si, vindas à luz em tempos diferentes, motivadas por fins diversos, difíceis de compreender, combinar e reconciliar entre si..$^{17}$

Essas debilidades, contudo, não seriam suficientes para afastar a possibilidade criativa da atividade judicial. À dificuldade contra majoritária ${ }^{18}$, de resto o principal e mais forte argumentos contra o ativismo judicial, Cappelletti oferece os seguintes contra-argumentos: (a) o sistema político também não alcança consenso entre os governados: os grupos políticos atuam na defesa de seus próprios interesses, como interesses individuais; (b) o poder judiciário não é completamente privado de representatividade; (c) os tribunais podem dar importante contribuição à representatividade geral do sistema; (d) as partes interessadas têm o exclusivo poder de iniciar o processo jurisdicional e determinar o seu conteúdo, cabendo-lhes ainda o fundamental direito de serem ouvidas. Nesse sentido, o processo jurisdicional seria mais participativo que os processos de escolha e tomada de decisão dos Poderes Executivo e Legislativo.

No sistema jurisdicional brasileiro, o derradeiro contra-argumento de Cappelletti à dificuldade contra majoritária deve ser recebido com ressalvas, uma vez que o controle concentrado de constitucionalidade, tal qual praticado entre nós, possibilita que os julgadores ultrapassem o conteúdo ditado pelas partes, seja do ponto de vista dos argumentos debatidos, seja no que diz respeito aos efeitos da decisão. Isso porque o Supremo Tribunal Federal é livre, no controle concentrado, que se caracteriza pelo exercício atípico de jurisdição (jurisdição objetiva), para debater argumentos não apresentados pelas partes e, até, ir além do pedido, bem como pode modular e alterar no âmbito material e temporal os efeitos da decisão.

Para John Hart Ely, tanto o interpretativismo como o não interpretativismo sofrem de um déficit de democracia ${ }^{19}$, sendo a questão mais problemática, talvez, com relação ao primeiro, já que se pretende que um texto ditado no passado regule a vida de novas gerações.

$[\mathrm{T}]$ he very attempt to make perpetual constitutions, is the assumption of a right to control the opinions of future generations; and to legislate for those over whom we have as little authority as we have over a nation in Asia. $^{20}$

\section{Um problema de restrições concretas}

Estabelecidos esses pontos, vê-se que os legisladores sofrem de limitações que, em muitos casos, não afetam os juízes, embora a legitimidade democrática afete de modo mais específico a estes, tenham eles uma

\footnotetext{
${ }^{17}$ Ibid., p. 83-84.

${ }^{18}$ Sobre a dificuldade contramajoritária cf. o clássico BICKEL, Alexander M. The least dangerous branch: the Supreme Court at the bar of politics. 2 ed. New Haven and London: Yale University Press, 1986, sobretudo o capítulo 1. Também VIDAL, Jânio Nunes. Elementos da teoria constitucional contemporânea: estudos sobre as constantes tensões entre política e jurisdição. Salvador: JusPodivm, 2009. Passim.

${ }^{19}$ ELY, John Hart. Democracy and distrust: a theory of judicial review. Cambridge and London: Harvard University Press, 2002. p. 11-12.

${ }^{20} \mathrm{G}$. Wood, The creation of American Republic, 1776-1787. Apud ELY, John Hart. Democracy and distrust: a theory of judicial review. Cambridge and London: Harvard University Press, 2002. p. 11.
} 
postura mais ativista ou de autocontenção. Segundo Cappelletti, o problema da legitimidade democrática é um problema de restrições concretas. "O verdadeiro problema não é portanto o de uma abstrata legitimação, mas é sobretudo um problema de restrições concretas. Quais restrições adota o juiz de particular lugar e tempo, em sua função (inevitavelmente) criativa de direito e valores?"21 Essa parece ser a pergunta fundamental para legitimar a atividade interpretativa e o ativismo judicial. Acrescento que não seria esse um problema apenas da legitimidade democrática, mas o problema da legitimação da atividade criativa dos juízes como um todo.

A dificuldade de se trabalhar com a ideia de restrições concretas é saber que espécies de restrições seriam adequadas e suficientes para a justificação do ativismo judicial: seriam restrições quanto às competências do órgão julgador? Neste caso, aos juízes constitucionais ou aos juízes das cortes superiores seria dada maior possibilidade de criar o direito, enquanto que, aos juízes de instâncias inferiores, menor possibilidade. Seriam restrições quanto à matéria? Nesse caso, o ativismo judicial somente seria justificável para a proteção dos direitos fundamentais, por exemplo; ou, ainda, como advoga Ely, para a implementação de procedimentos que assegurem maior nível de representatividade democrática.

Ely faz uma crítica do interpretativismo e do não interpretativismo e propõe uma atuação procedimental da Suprema Corte no judicial review capaz de garantir o processo de representação democrática, desobstruir os canais de mudança política e facilitar a representação das minorias. Essa proposta, todavia, não é isenta de críticas. É difícil estabelecer quando a decisão judicial contribui para garantir maior representação democrática e quando invade a esfera do Poder Legislativo, modificando o processo político. Além disso, uma interpretação mais restritiva do texto constitucional pode conduzir a uma solução mais conservadora em termos de mudanças políticas, como foi o caso da decisão sobre a lei da ficha limpa, Lei Complementar no 135, aprovada em 04 de junho 2010, que somente julgou válida a lei para as eleições de $2012^{22}$

No Brasil, a regulamentação do processo de representação e eleição dos representantes do povo é uma das áreas em que o Supremo Tribunal Federal tem sido mais criticado pelo excesso de ativismo. A título de exemplo, em 2006, o STF julgou inconstitucional dispositivo legal que estabelecia a cláusula de barreira ${ }^{23}$, que foi visto por muitos estudiosos como um retrocesso em oposição à uma reforma política que favorece

\footnotetext{
${ }^{21}$ CAPPELLETI, Mauro. Ob. cit., p. 103.

${ }^{22}$ STF. ADC 29, Relator(a): Min. LUIZ FUX, Tribunal Pleno, julgado em 16/02/2012, PROCESSO ELETRÔNICO DJe127 DIVULG 28-06-2012 PUBLIC 29-06-2012 RTJ VOL-00221- PP-00011. O argumento utilizado foi o de que o art. 16 da Constituição da República dispõe que "a lei que alterar o processo eleitoral entrará em vigor na data de sua publicação, não se aplicando à eleição que ocorra até um ano da data de sua vigência”. Uma interpretação, possível, contudo, seria a de que as inelegibilidades não tratam especificamente do processo político.

${ }^{23}$ ADI 1351, Relator(a): Min. MARCO AURÉLIO, Tribunal Pleno, julgado em 07/12/2006, DJ 30-03-2007 PP-00068 EMENT VOL-02270-01 PP-00019 REPUBLICAÇÃO: DJ 29-06-2007 PP-00031 RTJ VOL-00207-01 PP-00116.
} 
uma representação partidária mais forte e legítima. Assim também em temas como a fidelidade partidária e a verticalização das coligações partidárias, quando as decisões do Supremo Tribunal foram criticadas por invadir ou validar a invasão pelo Tribunal Superior Eleitoral da esfera do Poder Legislativo ${ }^{24}$.

E as restrições quanto ao método hermenêutico empregado? Segundo André Ramos Tavares, "a tradicional teoria do ativismo judicial da Justiça Constitucional estaria a preferir esse debate em termos de qual interpretação é mais adequada para o texto, ou seja, em termos de concorrência entre diversas teorias da interpretação" 25 . Tavares acredita que "a discussão acerca da legitimidade da Justiça Constitucional é correlata à temática da concepção hermenêutico-constitucional que deve guiar a atividade da Justiça Constitucional"26. Ainda assim, contudo, acreditamos que uma restrição que se funda na escolha de um método hermenêutico não é uma restrição adequada porque, a rigor, os juízes não estão vinculados à utilização deste ou daquele método.

\section{Os métodos hermenêuticos como legitimação da atividade criativa dos juízes}

O problema da legitimação do ativismo judicial pode ser abordado à luz de, pelo menos, dois enfoques distintos: (a) em primeiro lugar, perquirir se o ativismo judicial é possível ou desejável no âmbito de uma dada organização político-jurídica. Comumente esse primeiro ponto é discutido à luz de razões da filosofia política; (b) um segundo enfoque seria saber, uma vez concluindo-se pela possibilidade do ativismo judicial, como garantir um razoável grau de legitimidade às decisões judiciais que acabam por criar Direito, afastando-se do sentido mais literal e óbvio da norma jurídica. O primeiro enfoque é largamente abordado pela doutrina norte-americana, sobretudo nas controvérsias entre interpretativistas e não interpretativistas. É o segundo ponto, contudo, que nos interesse na presente investigação.

A legitimação do ativismo judicial, tem sido apresentada, sobretudo pela doutrina nacional e europeia, como um problema hermenêutico ou como metodológico. Para André Ramos Tavares,

um avanço, dentro de um espaço de segurança democrática, da atuação do juiz constitucional, pressupõe uma consolidação dos métodos de trabalho dessa instância, máxime quando representada por um Tribunal Constitucional que exerça com monopólio e definitividade a defesa e implementação da Constituição (no âmbito de normas ambíguas e vagas como ocorre comumente com os direitos fundamentais). ${ }^{27}$

Mendes, Coelho e Branco, em seu Curso de Direito Constitucional, abordam pelo menos seis métodos de interpretação constitucional e oito princípios de interpretação especificamente constitucionais, quase todos eles originários da doutrina alemã e alguns desenvolvidos e validados pela jurisprudência da Corte

\footnotetext{
${ }^{24}$ Cf. STF. MS's 26.602, 26.603, 26.604, ADI 3.999-DF e ADI's 2.626-DF e 3.685-DF.

${ }^{25}$ TAVARES, André Ramos. Paradigmas do judicialismo constitucional. São Paulo: Saraiva, 2012. p. 79.

${ }^{26}$ Ibid., p. 75.

${ }^{27}$ Ibid., p. 66.
} 
Constitucional Alemã ${ }^{28}$. Embora referidos autores reconheçam a riqueza desses métodos hermenêuticos, admitem o modo desordenado com que são utilizados pelos seus operadores e

a inexistência de critérios válidos que possam validar a escolha de seus instrumentos de trabalho, nem resolver os eventuais conflitos entre tais instrumentos, seja em função dos casos a decidir, das normas a manejar ou, até mesmo, dos objetivos que pretendam alcançar em dada situação hermenêutica. ${ }^{29}$

De fato, os métodos e princípios hermenêuticos não têm caráter normativo. A rigor, nem os juízes nem os advogados estão obrigados a utilizá-los, considerá-los ou segui-los na resolução dos casos concretos. Não quero com isso negar a importância do estudo de tais métodos ou a importância de sua utilização. $O$ ponto que gostaria de destacar é o de que a utilização desse ou daquele método hermenêutico não é capaz de legitimar, por si só, a interpretação do Direito, a criação do Direito pelos juízes e, portanto, o ativismo judicial. Acerca dos cânones de interpretação, na mesma linha, Robert Alexy destaca

não são, na realidade, regras. Não indicam o que se deve fazer ou o que se deve alcançar condicionada ou incondicionadamente. Por outro lado, são mais que simples pontos de vista ou linhas de investigação. A melhor forma de designá-las, para usar um conceito de Perelman é como esquemas de argumentos (schèmes d'arguments) ${ }^{30}$.

O problema da legitimação do ativismo judicial reclama uma solução para além dos métodos hermenêuticos que possam ser utilizados. Essa solução passa pela lógica, no sentido aristotélico do termo.

Nas palavras de Irving Copi, "o estudo da lógica é o estudo dos métodos e princípios usados para distinguir o raciocínio correto do incorreto" ${ }^{\text {"31 }}$. As regras da lógica argumentativa são regras cogentes - embora não juridicamente cogentes - na medida em que o descumprimento de uma regra lógica argumentativa importa em uma impossibilidade linguística demonstrável. Tais regras são uma real e factível restrição à atividade interpretativa dos juízes sem que, em um primeiro momento, apresente o inconveniente de estabelecer uma opção por este ou por aquele método hermenêutico.

\section{O pragmatismo de Richard Posner}

Segundo Richard Posner, diversas teorias constitucionais procuram justificar uma posição de maior ativismo ou maior autocontenção, tais quais o originalismo, o textualismo, o reforço da representação democrática de John Hart Ely, a living Constitution, a active liberty de Breyer, a leitura moral da Constituição e

\footnotetext{
${ }^{28}$ MENDES, Gilmar Ferreira; COELHO, Inocêncio Mártires; BRANCO, Paulo Gustavo Gonet. Curso de direito constitucional. 2 ed. São Paulo: Saraiva, 2008. p. $92-129$

${ }^{29}$ Ibid., p. 98-99.

${ }^{30} \mathrm{ALEXY}$, Robert. Teoria da argumentação jurídica: a teoria do discurso racional como teria da justificação jurídica. [Tradução Zilda Hutchinson Schild Silva. Revisão técnica da tradução e introdução à edição brasileira Cláudia Toledo]. 2 ed. São Paulo: Landy Editora, 2005. p. 239-240.

${ }^{31}$ COPI, Irving M. Introdução à lógica [tradução de Álvaro Cabral]. 2 ed. São Paulo: Mestre Jou, 1978. p. 19. 
tantas outras, mas nenhuma delas oferece soluções adequadas para a interpretação da constituiçãa ${ }^{32}$. Percebase que essas teorias aproximam-se fortemente dos métodos hermenêuticos desenvolvidos pela doutrina alemã e europeia, nenhum deles, contudo é capaz de oferecer soluções adequadas. O problema dessas teorias e métodos, ainda segundo Posner, é que não há nenhum método lógico ou empírico que permita escolher entre uma teoria constitucional e as outras ${ }^{33}$. Além disso, como já tivemos oportunidade de mencionar, a rigor, os juízes não estão obrigados a seguir nenhuma dessas teorias ou métodos.

Posner oferece como solução possível, então, a adoção do pragmatismo judicial, definindo-o como o método decisório que enfatiza as consequências da decisão sobre a doutrina. Para Posner, “[j] udges who don't insist that a legalistic algorithm will decide every case are what I call 'pragmatists', not in some pretentious philosophical sense but in the sense of an approach to decision making that emphasizes consequences over doctrine."34 Posner apresenta oito princípios do pragmatismo judicial que tentaremos resumir da seguinte forma:

1. O dever de decidir é o dever primário do juiz. $\mathrm{O}$ juiz não pode se recusar a decidir um caso somente porque não há guia em um texto legal;

2. O Direito não está limitado ao corpo das fontes ortodoxas, então a função jurisdicional não pode estar limitada a decidir os casos de acordo com tais fontes;

3. Nos casos em que as fontes ortodoxas não oferecem uma resposta para a questão jurídica em discussão, ou quando a resposta oferecida é insatisfatória, o juiz exerce o papel de legislador: cria direito que decide o caso e regula casos futuros similares;

4. Nenhuma teoria constitucional (método de interpretação) está disponível para guiar os juízes em seu papel de criar direito porque não há nenhum método lógico ou empírico que permita escolher uma teoria constitucional (método de interpretação) ao invés das outras. $\mathrm{Na}$ ausência de tais teorias, os juízes deveriam se guiar pelas conseqüências de suas decisões para as partes do caso, para as pessoas em situação similar e para o sistema como um todo;

5. O pragmatismo deve levar em conta não apenas as conseqüências das decisões para as partes, mas também os efeitos em valores tais quais continuidade, previsibilidade e estabilidade das normas legais e decisões;

6. Caso os juízes não saibam as conseqüências de suas decisões serão necessárias regras subsidiárias para lidar com a incerteza. Nesse caso, Posner tem como alternativa secundária o self-restraint tal qual defendido por Thayer.

7. O juiz deve tratar as partes do caso como partes representantes de todas as demais pessoas na mesma situação, devendo ignorar seu status social, méritos pessoais e influência política.

8. A decisão judicial deve trazer os fundamentos verdadeiros da escolha feita pelos juízes. Isso para prevenir que os juízes fundamentem suas decisões em consequeências que a sociedade não aceita como legítimos fundamentos para a decisão.

\footnotetext{
${ }^{32}$ Para uma visão panorâmica de algumas dessas teorias em sua dimensão legitimadora do judicial review cf. VIDAL, Jânio Nunes. Elementos da teoria constitucional contemporânea: estudos sobre as constantes tensões entre política e jurisdição. Salvador: JusPodivm, 2009. Cap. IV.

${ }^{33}$ POSNER, Richard A. The rise and fall of judicial self-restraint. In: California Law Review. Vol. 100. No. 3. June 2012. p. 519 556. Passim, sobretudo itens IV e V.

${ }^{34}$ Ibid., p. 539.
} 
Em linhas gerais, o pragmatismo preocupa-se com as consequências das decisões judiciais. Seriam, então, por seus resultados que a atividade criativa dos juízes seria ou não legitimada. Esses princípios e a própria adoção do pragmatismo ou consequencialismo são bastante controversos e merecem uma alentada discussão. De todo modo, a crítica de que o pragmatismo não estaria preocupado com os valores, mas somente com os resultados não é inteiramente aceitável, na medida em que a preservação e promoção de determinados valores ou o seu enfraquecimento e desrespeito são consequências das decisões judiciais que os julgadores precisam levar em consideração ${ }^{35}$. $\mathrm{O}$ argumento constantemente assacado contra o pragmatismo de que, com a sua adoção do raciocínio consequencialista, os juízes estariam validando o adágio maquiavélico de que os fins justificam os meios é uma simplificação grosseria do raciocínio proposto por Richard Posner.

É importante destacar que o consequencialismo vai estar sempre inserido em um jogo argumentativo que segue regras próprias. As consequências advindas de uma ou outra decisão, os valores que serão promovidos ou enfraquecidos deverão sempre ser demonstrados por dados minimamente objetivos, mas estarão sujeitos a um embate argumentativo. Em última análise, será a argumentação, as razões e as contrarazões oferecidas para fundamentar as decisões judiciais, ainda que essas razões sejam consequencialistas, que serão capazes de legitimar a atividade criativa dos juízes. Mesmo uma abordagem consequencialista não dispensa a consideração às regras lógico-argumentativas como instância de legitimação da atividade criativa dos juízes.

\section{A fundamentação da decisão judicial como legitimação do ativismo judicial}

Uma proposta de legitimação da atividade criativa dos juízes que leve em conta a argumentação deve se inserir no âmbito da fundamentação da decisão judicial, embora não esteja restrito a ele. A doutrina tradicional considera, aliás, que a legitimação do Poder Judiciário, repousa na adequada fundamentação das decisões judiciais. Como fazê-lo? Em um primeiro momento, poderíamos dizer que a decisão judicial seria legítima e não comportaria críticas por representar uma postura mais ou menos ativista se estivesse adequadamente fundamentada. Mas o que seria uma decisão adequadamente fundamentada?

\footnotetext{
${ }^{35}$ Para uma análise mais abrangente dessa perspectiva cf. ARGUELHES, Diego Werneck. Argumentos consequencialistas e Estado de Direito: subsídios para uma compatibilização. Disponível em < http://www.conpedi.org.br/manaus/arquivos/Anais/Diego\%20Werneck\%20Arguelhes.pdf >. Acessado em 19/11/2013. "Se as normas jurídicas podem ser interpretadas como uma exigência de transformação do mundo atual em um mundo possível por meio da introdução de um novo fato em cadeia causal, então é possível afirmar que o trabalho do juiz envolve necessariamente um componente de avaliação empírica consequencial. (...) A argumentação com base nas consequências pressupõe a adoção de algum critério para sua valoração; se quem avalia as consequências é o juiz, vinculado ao ordenamento jurídico, o que conta não são suas preferências, mas sim as preferências expressas pelas normas. Dadas duas possibilidades de decisão $(\mathrm{x} ; \mathrm{y})$, se a decisão $(\mathrm{x})$ promove o estado de coisas determinado pela norma aplicável em grau maior do que a decisão (y) (isto é, se as consequências de (x) contribuirão mais do que as de (y) para a efetivação desse estado de coisas), então a decisão (x) deve ser 'preferida' pelo juiz em detrimento de (y)". Op. cit., p. 14.
} 
Um dos mais percucientes estudos sobre essa questão e seus desdobramentos foi apresentada por Marcelo Guerra no artigo Notas sobre o dever constitucional de fundamentar as decisóes judiciais ( $C F$, art. $93,(X)^{36}$. Nesse estudo o autor pretende demonstrar a fecundidade da perspectiva inaugurada pela indagação "o que comanda a norma veiculada pelo art. 93, IX, CF?". A partir daí investiga extensamente o sentido da expressão "decisão fundamentada", sobretudo à luz de conceitos da filosofia da linguagem e da lógica. Para o autor, uma decisão seria correta quando estivesse adequadamente fundamentada e seria qualificada como adequadamente fundamentada quando observasse determinados critérios de correção previamente definidos.

Daí se poder dizer que uma decisão D é correta ou fundamentada se ela consistir na imposição de uma solução $S$ qualificada como correta à luz dos critérios de correção $\mathrm{Cn}+1$. Dito de outra forma, a correção da imposição da solução, na qual se traduz a decisão judicial, é dada pela correção da determinação cognitiva dessa solução como a correta. $^{37}$

Valendo-se do caso mais simples de decisão judicial, a saber, a declaração de existência de um direito subjetivo pelo juiz, o autor relaciona duas condições de existência de determinado direito subjetivo:

a) a existência de uma norma geral $\mathrm{N}$ que contenha a descrição do fato $\mathrm{F}$ como condição de sua incidência (e de existência do direito subjetivo);

b) a ocorrência do fato $\mathrm{F}^{38}$

Nesse caso simples, a decisão judicial seria correta e, portanto, fundamentada se, e somente se, fosse correta a declaração da existência da norma $\mathrm{N}$ e da ocorrência do fato $\mathrm{F}$. O problema é que a declaração da existência da norma $\mathrm{N}$ depende de pelo menos outras duas condições:

1) a declaração de que a norma $\mathrm{N}$ é o sentido veiculado pelo texto legislativo $\mathrm{T}$;

2) a declaração de que o ato legislativo $A$, que produz o texto legislativo $T$, é válido. ${ }^{39}$

Essas declarações, por sua vez, para serem corretas, dependem, como é fácil perceber, da existência de outras condições, em um processo de fundamentação que conduz a um regresso ao infinito. O mesmo ocorre com relação ao fato F: para que seja correto declarar a ocorrência do fato F, é necessário o preenchimento de duas condições:

i) A ocorrência do fato F está representada no MP1 [meio de prova 1] [...];

ii) O meio de prova MP é confiável.

A declaração de existência do fato F, para estar correta, também demanda o preenchimento de condições regressivas ao infinito. O problema, como se vê, é que os dois primeiros critérios de correção ((a) existência da norma $\mathrm{N}$; e (b) ocorrência do fato F) se desdobram em muitos outros, em níveis de fundamentação sucessivos, e tendem a um regresso ao infinito. $\mathrm{O}$ autor, então, apresenta pelo menos duas

\footnotetext{
${ }^{36}$ In: FUX, Luiz; NERY JR., Nelson; WAMBIER, Teresa Arruda Alvim (coordenadores). Processo e Constituição: estudos em homenagem ao professor José Carlos Barbosa Moreira. São Paulo: Revista dos Tribunais, 2006. p. 517-541.

${ }^{37}$ GUERRA, Marcelo Lima. Notas sobre o dever constitucional de fundamentar as decisóes judiciais (CF, art. 93, IX). In. FUX, Luiz; NERY JR., Nelson; WAMBIER, Teresa Arruda Alvim (coordenadores). Processo e Constituição: estudos em homenagem ao professor José Carlos Barbosa Moreira. São Paulo: Revista dos Tribunais, 2006.p. 517-541. p. 525.

${ }^{38}$ Ibid., p. 526.

${ }^{39}$ Ibid., p. 528.
} 
soluções para o problema do regresso ao infinito. A primeira delas consiste em argumentar que a norma que manda fundamentar as decisões judiciais, na verdade, não obriga os juízes a profeririam decisões completamente fundamentadas, mas, sim, obriga os juízes a proferirem decisões não equivocadamente fundamentadas. Do contrário, a interpretação da norma conduziria ao regresso ao infinito e, portanto, a um absurdo.

Com efeito, impõe-se reconhecer que é ao menos plausível considerar que, embora não seja possível - se e na medida em que não for resolvido o regresso ao infinito -, com um número finito de passos, demonstrar que uma decisão é correta, é possível, com um número finito de passos, demonstrar que ela é incorreta. Assim, a norma sob exame comandaria algo perfeitamente realizável: os juízes devem proferir decisóes não equivocadamente fundamentadas. ${ }^{40}$

É então que o autor se socorre da lógica do modo mais veemente e direto:

Os instrumentos desenvolvidos pela lógica (ou melhor: pelas várias lógicas, inclusive a informal) permitem, com um número finito de critérios de correção, demonstrar que uma decisão está não fundamentada ou incorreta, por ter violado o apontado modelo normativo. $^{41}$

A segunda solução proposta seria interpretar o mandamento constitucional de fundamentação das decisões judiciais como um mandato de otimização à luz da teoria das normas constitucionais de Robert Alexy, "assim restaria justificada a possibilidade de cumprir essa norma somente até certo ponto, e não "até o fim”, admitindo que a cessação dessa atividade em princípio infinita seja determinada pela obediência de outras normas do ordenamento".42

O estudo da fundamentação da decisão judicial como critério de legitimação e controle da atividade criativa dos juízes é de fundamental importância. Acrescentaríamos, contudo, uma perspectiva dialogal à proposta de Marcelo Guerra, que optou por analisar e definir a correção da decisão judicial a partir de uma perspectiva solipsista da atividade jurisdicional. Em verdade, a decisão judicial é fruto de um diálogo entre as partes e o julgador, por isso, além dos critérios apresentados pelo autor, outros devem ser levados em conta.

Uma decisão será correta e fundamentada à luz dos pedidos e dos argumentos apresentados pelas partes. A fundamentação relaciona-se não somente à questão jurídica em discussão absolutamente considerada, mas, sobretudo, às razões apresentadas pelas partes para que o juiz decida neste ou naquele sentido. Somente quando oferece razões suficientes aos argumentos apresentados pelas partes pode-se dizer que a decisão é correta ou adequadamente fundamentada. Tanto assim que a lei processual brasileira prevê o ônus de impugnação especificada dos fatos, à revelia, a existência de fatos incontroversos, o reconhecimento tácito do pedido etc. O dever de fundamentar a decisão judicial e a própria fundamentação da decisão judicial

\footnotetext{
${ }^{40}$ Ibid. p. 533.

${ }^{41}$ Ibid. p. 533.

${ }^{42}$ Ibid., p. 538.
} 
são, portanto, uma função do pedido e dos argumentos apresentados pelas partes, ainda que esta função relacione-se à existência da norma $\mathrm{N}$ e à ocorrência do fato $\mathrm{F}$.

A fundamentação da decisão judicial, na quase totalidade dos casos, é uma resposta aos argumentos das partes e só faz sentido falar em correção ou decisão adequadamente fundamentada uma vez estabelecidas as questões controvertidas e a extensão dessas questões. Em alguns casos, por exemplo, não há controvérsia quanto aos fatos, mas somente quanto à norma aplicável; em outros casos a controvérsia será somente quanto aos fatos e não quanto à norma; em outros ainda, haverá controvérsia tão somente quanto ao sentido da norma ou quanto à sua aplicação no tempo ou no espaço. Essa perspectiva seria capaz, inclusive, de oferecer uma solução mais simples e convincente para o problema do regresso ao infinito apresentado por Marcelo Guerra.

Já tivemos oportunidade de definir as questões jurídicas como "a controvérsia judicial cuja solução é capaz de resolver, com ou sem mérito, uma das lides autônomas da relação jurídica processual” ${ }^{43}$. Embora não seja conveniente aprofundarmos o estudo e a classificação das questões jurídicas no âmbito desse estudo, cabe destacar que a correta compreensão das questões jurídicas é essencial para se definir de modo adequado uma decisão jurídica fundamentada.

Por ora, gostaríamos de pontuar que a decisão será correta ou adequadamente fundamentada quando responder, do ponto de vista lógico-argumentativo, aos argumentos apresentados pelas partes. Isso não quer dizer, contudo, que haverá apenas uma decisão correta, mas que os argumentos utilizados pela decisão terão sido utilizados corretamente de uma perspectiva lógico-argumentativa e que, por isso, será fácil submetê-los ao escrutínio das partes, da comunidade acadêmica e dos demais órgãos do Poder Judiciário. Por meio desse exercício argumentativo transparente seria possível alcançar maior legitimidade na atividade criativa dos juízes.

\section{A argumentação como critério de legitimação e controle da atividade criativa dos juízes}

Quais regras argumentativas poderiam ser aplicadas para controlar a atividade criativa dos juízes? Como já dito, o objetivo desse estudo não é oferecer respostas definitivas a essa questão, mas ensaiar caminhos, abrir possibilidades. Em primeiro lugar, é preciso reconhecer que a aplicação das regras da lógica e

\footnotetext{
${ }^{43}$ JORGE NETO, Nagibe de Melo. Sentença cível: teoria e prática. 4 ed. Salvador: Editora JusPodivm, 2013. p. 165. "Há questões jurídicas que não são capazes de formar lides autônomas como, por exemplo, saber se há legitimidade passiva de um dos réus para a causa ou, ainda, saber se o autor tem interesse processual na causa. São questões preliminares meramente processuais. Por outro lado, não é qualquer ponto controvertido de fato ou de direito que pode ser considerado questão jurídica. Algumas vezes o ponto controvertido de fato é apenas o argumento capaz de solucionar a questão jurídica" (Ibid., p. 165). Ainda sobre a teoria da cognição judicial cf. DIDIER JR, Fredie. Curso de direito processual civil: introdução ao Direito Processual e Processo de Conhecimento. 15 ed. Salvador: Editora JusPodivm, 2013. Cap. IX.
} 
da argumentação, por óbvio, jamais será capaz de oferecer uma única solução correta para os casos difíceis, contudo será capaz de oferecer instrumentos para um controle mais rigoroso da atividade criativa dos juízes pelas partes, pela comunidade acadêmica e pelo conjunto da sociedade. Se duas decisões judiciais ou mesmo dois votos de uma mesma decisão colegiada apresentarem soluções divergentes será possível entender as razões de cada uma delas, analisar melhor os fundamentos apresentados e posicionar-se de modo crítico a favor ou contra a decisão. É esse processo dialético permanente que possibilitará o controle da atividade criativa dos juízes.

Ainda assim, poderíamos ventilar a existência de pelos menos três regras argumentativas que ressaem bastante evidentes:

a) a fundamentação da decisão judicial é função dos argumentos utilizados pelas partes, sendo assim, para acolher o pedido do autor, o juiz deve enfrentar os argumentos contrários ao pedido apresentados pela parte ré e que sejam logicamente incompatíveis com os argumentos utilizados na decisão. De igual modo, para julgar improcedente o pedido, o juiz deve enfrentar os argumentos do autor que sejam logicamente incompatíveis com o indeferimento do pedido. Isso não quer dizer que o julgador deve enfrentar todos os argumentos das partes. Algumas vezes um único pedido precisa da implementação de dois, três ou mais condições previstas na norma. Nesse caso, por exemplo, estando desatendida uma delas, o julgador estará suficientemente autorizado a julgar improcedente o pedido. As diversas possibilidades argumentativas, dado a sua variedade, somente podem ser examinadas em estudo próprio;

b) ao reformar uma decisão de instância inferior, a instância superior tem o dever de se livrar da carga de argumentação. É dizer: além dos argumentos das partes (regra (a)), se reforma a decisão da instância inferior, a instância superior tem o dever de enfrentar os argumentos apresentados pela instância inferior que são logicamente incompatíveis com os argumentos utilizados na decisão da instância superior;

c) os argumentos utilizados pelos juízes devem ser coerentes com os argumentos previamente utilizados em casos semelhantes decididos anteriormente. Onde a mesma razão, deve ser aplicado o mesmo direito (ubi eadem ratio, ibi idem jus).

As duas primeiras regras derivam dos princípios racionais da filosofia clássica e também podem ser demonstrados no campo da filosofia da linguagem, por isso são cogentes, pelo menos se estamos querendo nos referir a fundamentos e decisões racionais. Sem a sua aplicação, não se pode garantir a racionalidade da decisão judicial. Os princípios racionais têm por característica a universalidade, a necessidade e o caráter a priori. Segundo Alaôr Caffé Alves, a necessidade significa, no plano subjetivo, que tais princípios "são uma 
exigência absoluta da inteligência e são indispensáveis a qualquer operação intelectual. Sem eles a própria faculdade de conhecer inexiste" ${ }^{\prime 4}$. No plano objetivo, a necessidade dos princípios racionais significa que tais princípios "são leis do pensamento porque são primeiramente leis do ser. Disto resulta a concordância necessária entre o ser e o pensar, que faz com que não possamos admitir como possível no ser aquilo que o reconhecemos como contraditório no pensar." ${ }^{\text {45 }}$

A terceira regra deriva do princípio jurídico da igualdade. Não se pode tratar dois casos semelhantes de modo diferente. A coerência da decisão judicial com casos anteriores decididos pelo mesmo órgão judicial é um imperativo inafastável da igualdade, a não ser em casos em que a modificação do entendimento seja autorizada por outros argumentos lógica e juridicamente possíveis.

\section{CONCLUSÃO}

Não se discute a importância dos métodos hermenêuticos para a interpretação do Direito e a busca de soluções para os casos difíceis. Nenhum dos métodos hermenêuticos ou, como chama a doutrina norteamericana, nenhuma teoria constitucional (constitutional theories) será capaz de, isoladamente, fazer face ao problema da legitimação e controle da atividade criativa dos juízes. Também o consequencialismo resolve-se em um âmbito argumentativo.

A opção por um ou outro desses métodos resolver-se-á em um diálogo que ocorre no processo judicial entre o juiz e as partes. A fundamentação da decisão judicial é uma função do pedido e da atividade das partes, sobretudo dos argumentos utilizados pelas partes para fundamentar suas pretensões. Sendo assim, o respeito pelas regras e princípios da lógica argumentativa é inafastável como critério de legitimação da atividade criativa dos juízes. Pelo menos três regras lógico-argumentativas devem ser levadas em consideração para tanto:

a) enfrentamento dos argumentos apresentados pelas partes que sejam logicamente incompatíveis com os argumentos utilizados pela decisão;

b) a instância superior, quando reformar a decisão da instância inferior, deve enfrentar os argumentos utilizados pela instância inferior e que sejam logicamente incompatíveis com os argumentos usados pela instância superior;

c) os argumentos utilizados pelos juízes devem ser coerentes com os argumentos previamente utilizados em casos semelhantes decididos anteriormente. Onde a mesma razão, deve ser aplicado o

\footnotetext{
${ }^{44}$ ALVES, Alaôr Caffé. Lógica: pensamento formal e argumentação: elementos para o discurso jurídico. 4 ed. São Paulo: Quartier Latin, 2005. p. 158.

${ }^{45}$ Ibid. p. 158.
} 
mesmo direito (ubi eadem ratio, ibi idem jus), a não ser em casos em que a modificação do entendimento seja autorizada por outros argumentos lógica e juridicamente possíveis.

\title{
JUDICIAL ACTIVISM, DISCRETION AND CONTROL: A MATTER OF HERMENEUTICS?
}

\begin{abstract}
:
The article examines the problem of justification, legitimation and control of judicial activism from the traditional hermeneutical approach and proposes a new approach based on logical criteria and rules of argumentation.
\end{abstract}

Keywords: Judicial activism. Legitimation. Judicial decision. Reasons. Arguments.

\section{REFERENCIAS}

ALEXY, Robert. Teoria da argumentação jurídica: a teoria do discurso racional como teria da justificação jurídica. [Tradução Zilda Hutchinson Schild Silva. Revisão técnica da tradução e introdução à edição brasileira Cláudia Toledo]. 2 ed. São Paulo: Landy Editora, 2005.

ALVES, Alaôr Caffé. Lógica: pensamento formal e argumentação: elementos para o discurso jurídico. 4 ed. São Paulo: Quartier Latin, 2005.

ARGUELHES, Diego Werneck. Argumentos consequencialistas e Estado de Direito: subsídios para uma compatibilização. Disponível em < http://www.conpedi.org.br/manaus/arquivos/Anais/Diego\%20Werneck\%20Arguelhes.pdf >. Acessado em 19/11/2013.

BARBÉ, Vanessa. Le Human Rights Act 1998 et la souveranité parlamentaire. In: Revue Française de Droit Constitutionnel. Anne 2005. Vol. 61. Paris: Presses Universitaires de France, 2005. p. 117-145.

BICKEL, Alexander M. The least dangerous branch: the Supreme Court at the bar of politics. 2 Ed. New Haven and London: Yale University Press, 1986.

CAPPELLETI, Mauro. Juízes legisladores? [Tradução: Carlos Alberto Alvaro de Oliveira]. Porto Alegre: Sérgio Antonio Fabris Editor, 1993.

COPI, Irving M. Introdução à lógica [tradução de Álvaro Cabral]. 2 ed. São Paulo: Mestre Jou, 1978.

CUNHA JÚNIOR, Dirley da. O controle de constitucionalidade na França e suas alterações advindas da reforma constitucional de 23 de julho de 2008. Disponível em < http://portalciclo.com.br/downloads/artigos/direito/O_Controle_de_Constitucionalidade_na_Franca_ 
e_as_Alteracoes_advindas_da_Reforma_Constitucional_de_23_de_julho_de_2008.pdf $>$. Acessado em $19 / 11 / 2013$

DIDIER JR, Fredie. Curso de direito processual civil: introdução ao Direito Processual e Processo de Conhecimento. 15 ed. Salvador: Editora JusPodivm, 2013.

ELY, John Hart. Democracy and distrust: a theory of judicial review. Cambridge and London: Harvard University Press, 2002.

GUERRA, Marcelo Lima. Notas sobre o dever constitucional de fundamentar as decisões judiciais ( $C F$, art. 93, $L X)$. In: FUX, Luiz; NERY JR, Nelson; WAMBIER, Teresa Arruda Alvim (coordenadores). Processo e Constituição: estudos em homenagem ao professor José Carlos Barbosa Moreira. São Paulo: Revista dos Tribunais, 2006. p. 517-541.

JORGE NETO, Nagibe de Melo. O Controle jurisdicional das políticas públicas: concretizando a democracia e os direitos sociais fundamentais. Salvador: Edições JusPODIVM, 2008

Sentença cível: teoria e prática. 4 ed. Salvador: Editora JusPodivm, 2013.

KELSEN, Hans. Teoria pura do direito [Tradução: João Batista Machado]. São Paulo: Martins Fontes, 2003.

MENDES, Gilmar Ferreira; COELHO, Inocêncio Mártires; BRANCO, Paulo Gustavo Gonet. Curso de direito constitucional. 2 ed. São Paulo: Saraiva, 2008.

POSNER, Richard A. The rise and fall of judicial self-restraint. In: California Law Review. Vol. 100. No. 3. June 2012.p. 519-556.

TATE, C. Nela; VALLINDER, Torbjrn. The global expansion of judicial power. NewYork: NYU Press, 1997

TAVARES, André Ramos. Paradigmas do judicialismo constitucional. São Paulo: Saraiva, 2012.

VIDAL, Jânio Nunes. Elementos da teoria constitucional contemporânea: estudos sobre as constantes tensões entre política e jurisdição. Salvador: JusPodivm, 2009.

WARAT, Luis Alberto. O Direito e sua linguagem. 2 ed. Porto Alegre: Sergio Antonio Fabris Editor, 1995.

Trabalho enviado em 24 de fevereiro de 2014.

Aceito em 21 de abril de 2014. 